Artigo

\title{
La coexistencia en la diversidad Los conjuntos sociales del Chaco argentino durante la primera mitad del siglo 20, y sus formas de vinculación
}

\section{Coexistence in diversity}

The Argentine Chaco social groups during the first half of the twentieth century, and their ways of linking

Oscar Ernesto Mari*

Resumen: Este artículo investiga el proceso de colonización que tuvo el Territorio Nacional del Chaco en Argentina durante las primeras décadas del siglo 20. Se aborda el estudio de los diferentes grupos que poblaron especialmente el interior de este espacio durante el apogeo del ciclo algodonero, aludiéndose a sus características generales, a sus actividades laborales predominantes; sus formas de vida, modos de vinculación, e influencias en la identidad de esta jurisdicción.

Palabras clave: Chaco. Territorio. Colonización. Relaciones Sociales.

Abstract: This article investigates the process of colonization that took the National Territory of Chaco in Argentina during the first decades of the twentieth century. It addresses he different groups that inhabited this area during the height of the cotton cycle, alluding to their general profile, their predominant employment activities, their lifestyles, modes of attachment, as well as their influence on the identity of this jurisdiction.

Keywords: Chaco. Territory. Colonization. Sociability.

\footnotetext{
*Doctor en Historia, profesor ordinario en el departamento de Historia de la Facultad de Humanidades e investigador independiente del Conicet en el Instituto de Investigaciones Geohistóricas de la Universidad Nacional del Nordeste (IGHI-Conicet-Unne), en Resistencia, Chaco, Argentina <oscar.mari@yahoo.com.ar>.
}

Civitas, Porto Alegre, v. 16, n. 3, p. 522-539, jul.-set. 2016 


\section{Introducción}

La actual provincia de Chaco, ubicada en el Nordeste de Argentina, fue en su momento uno de los territorios nacionales organizados en 1884 para efectivizar la ocupación de los espacios periféricos por parte del estado. A semejanza de las otras unidades territoriales creadas simultáneamente, recibió un régimen político-institucional tutelado por el gobierno central, y se mantuvo en esa situación hasta su conversión en provincia a mediados del siglo 20.

Por lo general, estas jurisdicciones recibieron inmigración externa e interna para garantizar el poblamiento, y en buena medida, ello fue auspiciado por el estado nacional. Cabe destacar, sin embargo, que el proceso ocurrido en el Chaco revistió características especiales por el volumen de la afluencia humana y lo repentino de oleadas que habitualmente estuvieron asociadas a sus efervescentes ciclos económicos, y a las particulares modalidades de trabajo. Básicamente estos ciclos giraron en torno a la explotación forestal en una primera etapa, y en función de la producción algodonera en una segunda fase que se inició a principios de la década del veinte, y mantuvo su apogeo hasta comienzos de la década del cincuenta. Si bien esta segunda fase aceleró la incorporación inmigratoria, la ocupación espacial del Territorio, y llegó a eclipsar al primer período, ambos "ciclos" coexistieron y fueron en distintos grados, fuertes demandantes de mano de obra. En estos procesos, combinados con la relativa facilidad para acceder a la tierra pública, residió en buena medida el poder de atracción que ejerció el Chaco para los diferentes contingentes inmigratorios.

Decimos "diferentes", porque precisamente una de las características sobresalientes del Chaco de la primera mitad del siglo 20 fue la de haber sido el espacio receptor de una diversidad de nacionalidades y grupos provenientes de otros países y de distintas regiones de la Argentina. En parte es por ello que a nivel nacional, el Chaco fue conocido como un territorio que albergó a un "crisol de razas", como se decía en la época. La coexistencia de grupos tan diversos en espacios comunes como pueblos, parajes o colonias agrícolas, ha significado desde hace tiempo un tema de especial interés para nosotros, y es por ello que a través de sucesivas pesquisas nos hemos propuesto recrear las condiciones, formas de vida, e interrelación, de estos disímiles conjuntos sociales, particularmente durante sus primeros tiempos de residencia en este territorio. Una de las opciones para abordar este tema es a partir del estudio de las formas de vinculación que se fueron estableciendo entre los grupos que debieron sortear, a veces, antagónicas diferencias culturales. 
En este trabajo nos proponemos mostrar, dentro de las lógicas restricciones de un artículo, algunos aspectos de las formas de convivencia que se establecieron a partir de vínculos laborales, de proximidad espacial, o de sociabilidad en lugares o instituciones aglutinantes, y también desde luego, de las limitaciones que imperaron en cada caso. Para este fin nos valdremos de testimonios documentales que nos permiten recrear en el presente un pasado en donde comenzó a forjarse un cuerpo social tan heterogéneo, que hasta el día de hoy resulta difícil definirlo colectivamente.

En las páginas siguientes describiremos en primer lugar el contexto socioeconómico del Chaco durante las primeras décadas del siglo 20, para pasar luego al análisis de las formas de vida y vinculación surgidas en determinados ámbitos como producto de la coexistencia de grupos culturalmente muy distintos. Aludiremos al rol desempeñado por autoridades e instituciones en los procesos de integración, para finalmente proyectar la influencia de los diversos conjuntos en la construcción de una identidad social que aún no aparece claramente distinguible, como ocurre por ejemplo en otras provincias argentinas.

\section{El contexto socioeconómico del Chaco durante las primeras décadas del siglo 20}

Si bien la ley n. 1532 de 1884 organizó institucionalmente a los territorios nacionales argentinos dotándolos de un régimen político uniforme a manera de etapa preparatoria para su oportuna conversión en provincias, y otorgó al gobierno central un papel tutelar en su control, en el caso del Chaco el poblamiento "blanco" ya se había iniciado antes de la sanción de esta norma. En 1878 llegaron las primeras familias europeas que comenzaron la colonización de este espacio en su sector oriental, en cercanías de los grandes ríos del Este, y próximos al sitio en donde al poco tiempo se erigiría formalmente la capital del Chaco: Resistencia. Este nombre simbolizó lo que durante algunos años más sería la actitud que debieron mantener los pioneros ante un medio geográfico en principio inhóspito, y sobre todo, frente a la hostilidad de los indígenas.

A esta primera etapa se la denomina fundación, porque precisamente en ella se levantaron los primeros pueblos y colonias juntamente con el afincamiento de los primeros grupos de inmigrantes italianos y españoles. A partir del siguiente ciclo llamado forestal se inició a fines del siglo 19 la extracción de maderas y de tanino, siempre en la sección sud-oriental, mientras ya se concebían planes para la incorporación del vasto interior de este territorio mediante la combinación de avanzadas militares contra los indígenas aún no reducidos, y la construcción de vías férreas para comunicarlo con el resto del país. 
Estas acciones se desarrollarían entre fines de la primera década del siglo 20, y una parte de la segunda, mientras las actividades forestales en pleno apogeo continuaban atrayendo importantes contingentes de trabajadores desde los espacios vecinos, como por ejemplo la provincia de Corrientes (cruzando el río Paraná), y el Paraguay, en la opuesta orilla del río homónimo. De esta forma, correntinos y paraguayos pasaron a constituir desde un primer momento una parte importante del componente social que se estaba formando en el Chaco.

Cuando promediaba la segunda década del siglo 20, comenzaron a producirse en el Chaco una serie de eventos concatenados que darán inicio a un nuevo "ciclo" económico. La culminación de las campañas militares que redujeron a los aborígenes; la terminación de las vías ferroviarias troncales que conectaron al Chaco con el resto del país en dirección oeste y norte; la incorporación de nuevas tierras aptas para la colonización agrícola; la fuerte valorización del algodón en los mercados internacionales, y una nueva apertura inmigratoria promovida por el Estado, serán los acontecimientos secuenciales que dieron origen al llamado ciclo algodonero. Es precisamente durante esta etapa cuando se produce el aluvión inmigratorio, en parte fomentado por el estado (en lo que concierne a los europeos), y en parte como una consecuencia natural de la dinámica generada por el proceso (en lo referido a la inmigración interna).

Si bien durante el ciclo forestal el incremento demográfico había sido significativo, las cifras se tornan moderadas al compararlas con lo ocurrido durante el período algodonero. Según censos oficiales, en 1914 había 46.274 habitantes en el Chaco, y en 1920 ya eran 60.564. Desde ese año, en que prácticamente se inicia la etapa vinculada al cultivo del textil, la población pasa a 214.160 habitantes en 1934. Dos años más tarde ya son 314.000; en 1940 se estimaban en 360.000 , y en 1947 ya alcanzan a 430.555 habitantes. $^{1}$

Como puede apreciarse, en pocos años hubo un crecimiento poblacional formidable, y todo este volumen de personas foráneas se radicó fundamentalmente en las zonas centrales y del oeste del Chaco (recientemente incorporadas), en donde se produjo precisamente el vertiginoso proceso colonizador vinculado a la explotación del textil. Dentro de estas miles de personas arribadas, hubo numerosos europeos que en esta segunda etapa - y a diferencia de la primera -, no fueron sólo españoles e italianos, sino también alemanes, checoeslovacos, polacos, yugoslavos, rusos, búlgaros, y húngaros, por citar sólo a las colectividades mayoritarias. A ellos se añadieron también

\footnotetext{
${ }^{1}$ Datos tomados de los censos y estimaciones oficiales (locales y nacionales) de los años respectivos.
} 
en esta época los grupos provenientes de las provincias vecinas del Chaco, como Corrientes, Santiago del Estero, Salta, Santa Fe, y desde luego, del Paraguay, quienes vinieron a participar del proceso fundamentalmente en carácter de "braceros", es decir, jornaleros que se dedicaron a desmalezar las plantas de algodón, y a recoger los capullos en el período de zafra. Estos conjuntos humanos se radicaron especialmente en los departamentos denominados Napalpí y Campo del Cielo, en el centro-oeste del Chaco, en donde precisamente floreció la actividad algodonera. A la sazón, fueron éstos departamentos los que tuvieron el mayor crecimiento poblacional durante estos años.

Y aunque los inmigrantes internos venían con la intención de participar sólo temporalmente de las labores inherentes al cultivo del textil para regresar luego a sus lugares de origen, un buen número de estos trabajadores se quedaba a vivir en el territorio al término de cada campaña. Ello explica el crecimiento demográfico sostenido del Chaco en estos años, y también el mosaico "multiétnico" en el que se convirtió este territorio en muy poco tiempo.

Figura 1. Territorio nacional del Chaco 1935-1940

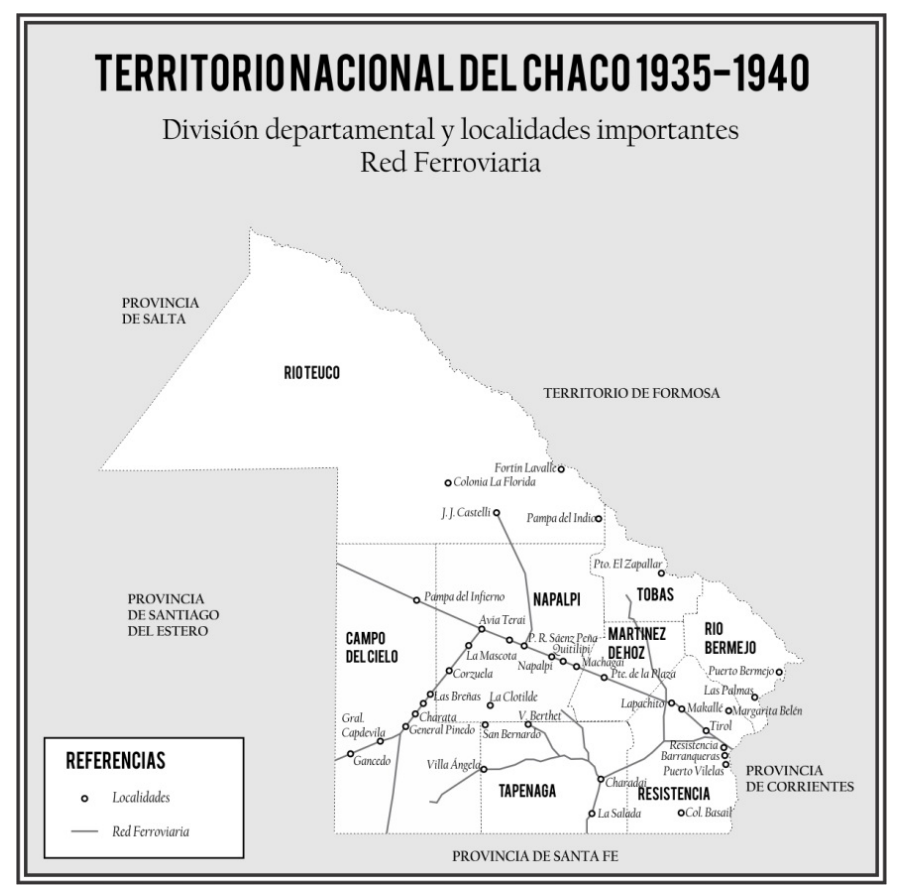

Fuente: Elaboración propia. 


\section{Las características generales del componente social arribado al Chaco}

Ciertamente es un desafío tratar de caracterizar en pocas líneas a los diferentes grupos humanos arribados al Chaco para participar de sus efervescentes ciclos económicos, pero ésta es una tarea ineludible para poder perfilar el comportamiento de los mismos, y su relación con el ambiente natural y social.

En principio debemos distinguir entre los inmigrantes de origen europeo, y aquellos que provinieron -por lo general- de regiones circundantes a este territorio. Esta distinción se hace necesaria por algunos motivos: las diferencias culturales e idiomáticas; las tipologías físicas, e incluso el rol que tuvieron grupalmente en las especificidades laborales del Chaco, hicieron que los procesos de adaptación y de vinculación tuvieran ritmos distintos en cada caso, por obvias razones.

En lo que respecta a los europeos, debemos decir que en la segunda corriente inmigratoria que se instaló fundamentalmente en el interior del Chaco, los españoles e italianos continuaron siendo las colectividades predominantes, de la misma manera que lo fueron también a nivel nacional. Dada su afinidad cultural con la sociedad receptora, estos grupos tuvieron una rápida integración, a punto tal, que llegaron a sentirse más argentinos que los propios nativos. Se dedicaron a una diversidad de oficios; no tuvieron mayores reparos para relacionarse con las demás colectividades, y menos aún con los criollos, de los cuales adoptaron rápidamente algunas de sus costumbres. Tampoco tuvieron inconvenientes en casarse con argentinas nativas, aunque en este sentido deben tenerse en cuenta los altos porcentajes de masculinidad existentes entre los grupos europeos, lo cual facilitó los matrimonios exogámicos. Se caracterizaron por su energía, tesón, y vivacidad en los emprendimientos y en las relaciones sociales, y una muestra de su fuerte presencia en el Chaco se observó, por ejemplo, en los almacenes de Ramos Generales muy comunes en esta época, cuyos propietarios fueron especialmente, familias de italianos y españoles. Fundaron las primeras asociaciones mutualistas en este territorio, las cuales como veremos más adelante, oficiaron también de lugares de vinculación interétnica. ${ }^{2}$

\footnotetext{
${ }^{2}$ Las publicaciones chaqueñas de la época describían, por ejemplo, al italiano promedio afincado en el Chaco como: "[...] un exponente fiel del trabajo y de la perseverancia llevados hasta el grado de la rudeza [...] Siembra la tierra y construye pueblos sin saber porqué, mientras le da al país el esfuerzo para enriquecerlo. Se identifica de tal manera con nuestros hábitos y costumbres, que al poco tiempo parece rivalizar con nosotros por la preeminencia del aire nacional [...]" (Gobierno del territorio nacional del Chaco. Álbum gráfico descriptivo, Bs. As. 1935, p. 97).
} 
Otra de las colectividades importantes arribadas en esta etapa fue la de los checoslovacos, quienes se instalaron mayoritariamente en la localidad de Sáenz Peña y colonias circundantes, en donde prontamente fueron reconocidos por su laboriosidad, mesura, y cultura general. Aunque una porción de ellos se dedicó a los trabajos agrícolas, en general se abocaron a una diversidad de oficios, tanto en el ámbito rural, como en el urbano. En Sáenz Peña llegaron a poseer una imprenta que publicaba un periódico en su propio idioma; iglesias, y casas comerciales de distintos rubros, así como profesionales que ocuparon los oficios más calificados.

A su vez, los yugoslavos tuvieron también un peso importante en el componente inmigratorio de esta etapa, particularmente en la zona central del Chaco. Se dispersaron un poco más que los checoslovacos, radicándose en los alrededores de las localidades de Sáenz Peña, Quitilipi, Corzuela, Las Breñas, Villa Angela, y Campo Largo. En cercanías de la primera ciudad lograron constituir una próspera colonia denominada José Mármol, aunque fue mayormente conocida como La Montenegrina, en alusión a los integrantes provenientes de esa región.

Respecto a los germanos, deben distinguirse entre los que vinieron directamente de Alemania, quienes se instalaron en los alrededores de Charata, y aquellos que provinieron del sur de Rusia denominados "alemanes del Volga", y que desde hacía algún tiempo ya estaban radicados en el territorio nacional de la pampa. Éstos debieron emigrar a causa de una persistente sequía, y en los inicios de la década del treinta se instalaron en las colonias agrícolas Castelli y La Florida, que fueron creadas en el norte del Chaco, en el departamento Río Teuco.

Un buen porcentaje de ucranianos se instaló, a su vez, en el centro del Chaco, en la zona comprendida entre Sáenz Peña, Las Breñas, San Bernardo, y La Tigra. Los búlgaros, por su parte, se concentraron en los alrededores de Las Breñas, y en determinado momento esta colectividad adquirió un fuerte protagonismo al participar una parte de sus miembros en los movimientos huelguísticos agrarios que inquietaron al Territorio en mitad de esta década.

Los polacos fueron también una colectividad muy numerosa, y aunque se agruparon en apreciables cantidades en las colonias circundantes a Las Breñas, Sáenz Peña y Charata, el historiador Hugo Beck asegura que las labores agrícolas no fueron su principal actividad, sino que se dedicaron fundamentalmente al comercio en los centros urbanos (Beck, 2001).

Hemos mencionado fundamentalmente a los grupos más significativos ingresados en esta segunda etapa inmigratoria, pero no podemos dejar de mencionar que otras colectividades como las de los húngaros, austríacos, 
franceses, suizos, israelitas, o sirio-libaneses -por nombrar sólo algunas-, tuvieron una importante presencia en el Chaco, aunque no hayan sido tan visibles debido a su menor número y dispersión espacial.

Tabla 1. Inmigrantes europeos ingresados al Chaco entre 1920 y 1947

\begin{tabular}{lccc}
\hline \multicolumn{1}{c}{ Nacionalidades } & $\mathbf{1 9 2 0}$ & $\mathbf{1 9 3 4}$ & $\mathbf{1 9 4 7}$ \\
\hline Españoles & 2.731 & 5.532 & 5.220 \\
Italianos & 1.411 & 2.813 & 2.500 \\
Rusos & 205 & 2.557 & 3.596 \\
Polacos & $\mathrm{S} / \mathrm{D}$ & 2.095 & 4.851 \\
Checos & $\mathrm{S} / \mathrm{D}$ & 1.628 & 1.669 \\
Yugoslavos & $\mathrm{S} / \mathrm{D}$ & 1.484 & 2.330 \\
Alemanes & 241 & 1.425 & 919 \\
Búlgaros & $\mathrm{S} / \mathrm{D}$ & 1.235 & 1.655 \\
Húngaros & $\mathrm{S} / \mathrm{D}$ & 451 & 410 \\
Austríacos & 339 & 311 & 660 \\
Franceses & 363 & 283 & 222 \\
Suizos & 105 & 159 & 162 \\
Británicos & 77 & 42 & 32 \\
Otros europeos & 308 & 545 & 892 \\
Totales & 5.780 & 20.560 & 25.158 \\
\hline
\end{tabular}

Fuente: Beck (2001, p. 77), en base a los censos locales y nacionales de estos años.

Esta afluencia inmigratoria europea, mucho más relevante por su heterogeneidad que por su volumen, fue sin embargo forjando la imagen de un Chaco gringo ante la sociedad nacional, lo cual en cierta forma constituyó un punto a favor para un territorio que hasta hacía poco había estado asociado a la imagen de una tierra inhóspita y salvaje como consecuencia de las vicisitudes de la lucha contra un medio geográfico, e indígenas hostiles. Hacemos esta aclaración, porque el número de los inmigrantes internos y de los provenientes del Paraguay fue bastante mayor que el de los europeos, pero la visualización de los europeos sobresalía no sólo por sus tipologías físicas particulares, sino sobre todo, por el despliegue de actividad que los caracterizaba. Dados sus niveles de iniciativa, dedicación al trabajo, y manejo de las actividades productivas, industriales, y comerciales, su presencia apareció mucho más nítida frente al mundo de los criollos, que aún siendo numéricamente 
superiores, tendían a invisibilizarse por la propia naturaleza de sus tareas (dependientes de los primeros), y por sus discretos ritmos de vida diarios. Aún a los observadores más atentos de la época les resultó difícil sustraerse a esta impresión al describir a los conjuntos sociales de Chaco en particular, y de los territorios nacionales en general.

Avanzada la década del cincuenta, el historiador chaqueño Guido Miranda decía todavía que a primera vista algunas poblaciones del Chaco parecían estar integradas exclusivamente por extranjeros, porque quienes conducían los carros y tractores; las casas comerciales, talleres y chacras, eran mayoritariamente inmigrantes europeos, o bien sus hijos, los cuales además de tener un extraordinario parecido físico, conservaban el idioma, y también los hábitos de sus padres (Miranda, 1955, p. 278).

Obviamente, esta mayor visibilidad de los "gringos" derivada en parte de su dinamismo, tenía una explicación que excedía sus aptitudes culturales. La mayoría de estos inmigrantes había dejado atrás una situación muy precaria en sus respectivos países de origen, y la urgencia por revertirla en esta nueva tierra hizo que desplegaran una actividad febril en cada uno de sus oficios o emprendimientos. Y aún cuando consiguieron sus objetivos en plazos relativamente breves, sus ritmos de trabajo se mantuvieron constantes y fueron emulados por sus descendientes.

Pero como hemos dicho, estos "gringos" no fueron los únicos que poblaron el interior del Chaco en esta época. Hubo otros conjuntos provenientes de espacios circundantes que tuvieron una significativa influencia en la conformación de esta incipiente sociedad. Así como hemos visto que los inmigrantes europeos manejaron en general las actividades y oficios más calificados (o rentables), y también fueron los "propietarios" en su mayoría, de la misma forma, quienes aportaron la "mano de obra" y se desempeñaron como empleados o peones de los primeros, fueron los migrantes internos, especialmente los criollos venidos desde las provincias colindantes. Si bien esta realidad laboral no era desconocida en el Chaco, al difundirse el cultivo algodonero esto se manifestó con mayor claridad debido a las propias características de la explotación del textil. El cultivo de algodón requería en esta época una constante intervención del hombre. La siembra, el desmalezado permanente, el "curado" o fumigado, y finalmente la cosecha en sus -generalmente- dos recolecciones casi continuas, se hacían manualmente, y demandaban por lo tanto, un considerable número de jornaleros. Al expandirse las áreas de cultivo durante las décadas del veinte y treinta se debió recurrir a alicientes para conseguir mano de obra desde otros espacios. Hubo en este sentido acciones de promoción mediante el suministro gratuito de pasajes 
ferroviarios para atraer esta fuerza laboral, cuya escasez, llegó a ser crítica en algunas temporadas.

De esta forma comenzó a hacerse más habitual el periódico ingreso de miles de cosecheros que, acompañados por sus respectivas familias, venían al Chaco a alquilar su trabajo. En orden de importancia numérica, sobresalieron los correntinos, santiagueños, salteños, paraguayos, y santafesinos. Estos permanecían varios meses en el Chaco, y en muchos casos, se afincaban definitivamente al terminar la temporada. Durante los años de esplendor del cultivo a mediados de la década del treinta se necesitaron alrededor de treinta mil braceros foráneos para satisfacer la demanda de mano de obra. A ellos se agregaron miles de transeúntes que por motivos siempre ligados a la actividad en expansión, transitaban por el Chaco en busca de oportunidades laborales o de negocios. Este flujo de personas desbordó una y otra vez la capacidad administrativa local, y la manifestación más elocuente pudo notarse particularmente en las dificultades para ejercer un adecuado control social en sus diversos aspectos.

Dado que los contingentes que intervinieron en las tareas manuales de ambos ciclos (forestal y algodonero) estuvieron compuestos mayoritariamente por correntinos y santiagueños, no está demás caracterizarlos en general para entender mejor sus respectivas influencias en este espacio. Al provenir de ámbitos geográfica y culturalmente muy distintos, su idiosincrasia, sus maneras de trabajar y de relacionarse, fueron también sustancialmente diferentes. Quienes han descripto en esta época a los trabajadores típicos provenientes de una u otra provincia remarcaron certeramente sus particularidades, muchas de las cuales son, hasta hoy, características reconocidas de los tipos sociales correntinos y santiagueños. Ya durante el período de preeminencia de los obrajes forestales podían distinguirse claramente ambos grupos entre los hacheros que integraban esos enclaves. Eran diferenciados por su apariencia física, sus maneras de hablar y de vestirse, sus costumbres, régimen de vida; sus habilidades, ritmos de trabajo, y hasta por el trato que tenían con la parte patronal. Los correntinos eran expresivos, vivaces y activos, con inclinación natural a la rebeldía, y con un consolidado sentido del honor que los hacía ofenderse fácilmente y reaccionar con temeridad hasta con sus patrones.

Los santiagueños, en cambio, eran más tranquilos y menos manifiestos, pero mucho más perseverantes. $Y$ así como se elegía a los vigorosos correntinos para voltear un quebracho ${ }^{3}$, se seleccionaba a los menos fuertes pero más

${ }^{3}$ El "quebracho colorado" es un árbol propio del norte de Argentina, y particularmente abundante en el Chaco de esta época. Tiene una de las maderas más duras que existen (quiebra-hacha), y de él se obtiene tanino curtiente de óptima calidad. 
pacientes santiagueños para el "labrado", que consistía en descortezar y dar forma a postes, vigas y durmientes. Similares distinciones pudieron establecer los ingenieros Mata y Franchelli en su publicación sobre el cultivo algodonero a fines de la década del treinta. ${ }^{4}$

Al referirse al comportamiento laboral de unos y otros decían, por ejemplo, que los correntinos usualmente se dirigían a la cosecha en el Chaco más por costumbre, que por el afán de obtener un beneficio económico. Respaldaron esto al comentar que no tenían inconvenientes en ausentarse de sus tareas para retornar a sus lugares de origen si es que había alguna fiesta o celebración, aunque ello les significara pérdidas de días de trabajo. Decían que era normal que al final de la temporada regresaran a su provincia sin llevar ni un centavo de lo ganado. En cambio los santiagueños -aseguraban-, eran mucho más interesados y cuidadosos en el manejo de sus recursos. Durante la campaña procuraban obtener el mayor rédito posible, aún a costa de privaciones autoimpuestas, para regresar luego a sus lugares con un razonable peculio que les permitiera mantenerse algunos meses, o encarar algún emprendimiento. Estos conjuntos constituyeron una parte significativa del poblamiento del Chaco, ya que al término de cada campaña, parte de ellos se emplearon como peones o puesteros a esperar la siguiente temporada, iniciando de esta forma un proceso de arraigo en este territorio. Culturalmente también tuvieron una influencia decisiva, ya que impusieron en este ámbito un conjunto de tradiciones y costumbres características de sus lugares de origen, que hasta hoy son fácilmente perceptibles en distintas zonas del Chaco.

\section{Los modos de vinculación y sociabilidad en un multiétnico escenario}

Considerando el escenario descripto, una de las preguntas que nos hemos formulado consistió en saber cuáles fueron las formas o mecanismos que utilizaron para relacionarse estos conjuntos tan diferentes desde el punto de vista cultural. Respondiendo a este interés deberíamos recordar que desde sus inicios, el poblamiento del Chaco se realizó bajo los lineamientos de un programa de colonización que fomentó deliberadamente una inmigración heterogénea hacia un espacio nuevo en donde no había población "blanca".

\footnotetext{
${ }^{4}$ Los ingenieros agrónomos Rafael García Mata y Rómulo Franchelli, en su condición de representantes de la Junta Nacional del Algodón, hicieron entre 1939 y 1941 una precisa evaluación las cuestiones vinculadas a este cultivo intentando demostrar las ventajas que reportaría la mecanización de la cosecha algodonera para resolver, entre otras cosas, la problemática humana devenida de las tareas manuales de zafra. Como resultado de sus estudios publicaron el libro Cosecha mecánica del algodón, en 1942.
} 
Por tal motivo, al momento de la ocupación no existían prejuicios de ningún tipo, y si a ello se agrega que el movimiento poblador se produjo en períodos muy breves, puede deducirse que nadie estuvo en condiciones de esgrimir jerarquías o posiciones de privilegio basadas, por ejemplo, en un mayor tiempo de residencia. De este modo, los ingresos aluviales operaron desde un principio como una fuerza, igualadora que no dejaba margen para la invocación de linajes o alcurnias, siendo el progreso material el único modo de posicionarse o ascender en esta sociedad en vías de formación.

El ámbito rural fue un escenario representativo para apreciar en su expresión más prístina los modos de relación a nivel colectivo. Es que allí es donde se instalaron la mayoría de los grupos aquí descriptos, ya que las actividades que los atrajeron fueron esencialmente agrícolas, y dentro de ellas, las vinculadas específicamente a la explotación algodonera. En ese espacio podemos encontrar una síntesis de los procesos de integración multiétnica que se dieron en el Chaco, y que pueden aplicarse perfectamente a los ámbitos urbanos, ya que éstos fueron una extensión de la vida en el campo y no existieron mayores diferencias de trato en las relaciones interpersonales.

Si nos situáramos entre las décadas del veinte y treinta en el Chaco, observaríamos un escenario en donde la confluencia multiétnica desbordaba las colonias agrícolas creadas alrededor de los pueblos recientemente fundados, especialmente en los departamentos Napalpí y Campo del Cielo. Sólo para dar una idea, entre 1920 y 1934 la población del primero de ellos pasó de 5.552 habitantes, a tener 50.652 , es decir que prácticamente se decuplicó la población en apenas catorce años. Durante los primeros tiempos estos grupos buscaron consolidarse en sus actividades u oficios, pero una vez logrado esto, que en el Chaco de ese entonces no llevó más de cuatro o cinco años, hubo una mayor disposición para emprender algunas rudimentarias formas de sociabilidad.

En el caso de los inmigrantes europeos, la sociabilidad estuvo inicialmente circunscripta al propio grupo étnico, para evolucionar luego a un relacionamiento intergrupal. Como ya señaláramos, dicho proceso de apertura demandó un período de tiempo variable según el origen de los mismos, siendo bastante más lento en el caso de los germanos y eslavos. Los ámbitos de vinculación colectiva que se fueron organizando bajo ciertas formas institucionales se derivaron de necesidades de asociación para asistirse recíprocamente y defender intereses comunes. Las sociedades de socorros mutuos, y más aún, las cooperativas agrícolas, fueron ejemplos representativos de esta tendencia, y dichas agrupaciones pasaron a actuar prontamente como canales de contacto social entre individuos o familias que no disponían de otras 
opciones de relación por vivir en el ámbito rural. Las sociedades mutualistas fueron las primeras instituciones que posibilitaron la interrelación social en el espacio rural, y como es de esperar, surgieron tempranamente durante la primera etapa colonizadora, en el sector oriental.

En la segunda fase de poblamiento, ya con nuevas nacionalidades incorporadas, una de las primeras instituciones de este tipo fue la que fundaron los checoslovacos en Sáenz Peña con el nombre de Slavia, en 1917. Los alemanes harían la suya en Charata con el nombre de Unión Germánica, en 1920; los montenegrinos formarían su centro en la colonia homónima en 1927; los búlgaros lo harían en 1929 en Las Breñas; los húngaros constituirían su Sociedad de Cultura y Socorros Mutuos en 1931 en Villa Angela, y años más tarde, búlgaros y yugoslavos harían lo mismo, pero en Sáenz Peña. Si bien hemos aludido a las nuevas colectividades ahora presentes, no debemos olvidar que tanto italianos como españoles continuaron siendo los inmigrantes europeos mayoritarios, y desde luego también crearon sus propios centros en distintos puntos del Chaco. Y aunque podría pensarse que estas instituciones albergaron a sus propios paisanos, ello no fue así, ya que desde sus inicios se constituyeron en espacios pluralistas. Y si bien buena parte de las sedes se edificaron en las áreas urbanas, el vínculo con los pobladores rurales fue siempre muy estrecho, ya que generalmente las colonias se hallaban muy cerca de los pueblos. Pero las que sí tuvieron un contacto directo y regular con el mundo rural fueron las cooperativas agrícolas, no sólo por la propia naturaleza de sus actividades, sino también por sus lugares de emplazamiento. Estas asociaciones también se empezaron a constituir por iniciativa de los pioneros durante la primera etapa colonizadora, pero a raíz del apogeo algodonero se expandieron notablemente en el interior del Territorio a partir de la década del veinte. En 1934 eran 16; en 1940 ya eran 24, y a finales de esa década llegarían a ser 32 cooperativas (Beck, 2001, p. 112). Parte de ellas se instalaron en los departamentos más ligados al cultivo algodonero y a la colonización, y llegaron a tener como asociados al $75 \%$ de los agricultores, combinando europeos y criollos. Por ello es que dentro de la vida de estas cooperativas es donde más se notó el proceso de integración social ocurrido en el Chaco. Allí confluyeron pobladores y colonos de distintos orígenes; individualmente o con sus respectivas familias. Eran centros de acopio, de abastecimiento; de intercambio comercial, y también de interrelación social. El historiador chaqueño Guido Miranda supo sintetizar con exactitud el funcionamiento de estas cooperativas, y sobre todo, su significado como centros aglutinantes cuando describió en su libro Tres ciclos Chaqueños, el evento extraordinario que representaban las particulares "asambleas anuales" 
Todos los años, sean cuales fueran las circunstancias que acompañan el ciclo de la producción algodonera, hay un día en que se paralizan los trabajos en las chacras; toda la familia, inclusive los peones, se acicala con la mejor vestimenta y parte en carros, sulkys o volantas para asistir a un acto que tiene lugar en el pueblo, y que dura desde la mañana hasta altas horas de la noche: es la Asamblea Anual Ordinaria de la Cooperativa. Siempre hemos contemplado con emoción estas vastas asambleas públicas, celebradas en los galpones de zinc que sirven para almacenar la fibra o la semilla de algodón. Son un acontecimiento característico del Chaco: cientos de socios de la más heterogénea condición...; agricultores, viejos, hijos, o viudas que siguen con la labor, se reúnen a discutir intereses comunes... Diferencias de idioma, origen situación, educación y temperamento dificultan a veces la tarea social de las cooperativas, pero el movimiento crece entre dramáticos tanteos, desfallecimientos y avances (Miranda, 1955, p. 259-260).

Por haber asistido a estos eventos en algunas cooperativas del Chaco podemos respaldar estas descripciones, y agregar por ejemplo, que una vez finalizada la reunión formal, en las primeras horas de la tarde se iniciaba el banquete en el cual tomaban parte todos los aledaños, aunque no fueran socios de la entidad. Aquí residía el "valor social" de estos eventos; en representar una oportunidad de congregar a grupos multiétnicos que, al residir en ámbitos rurales, no tenían muchas ocasiones de contacto colectivo. Precisamente durante estos eventos se iniciaban amistades o relaciones parentales, sobre todo entre gringos y criollos, debido a la dilución de las barreras idiomáticas y/o prejuicios entre las nuevas generaciones, que ya eran argentinos de nacimiento.

Pero al margen de estas formas de vinculación en las que algunas instituciones actuaron como nexos, hubo sin embargo otros espacios en los que esta interrelación debió entablarse sin la intermediación de estas entidades. Estas situaciones se dieron en los parajes más alejados del ámbito rural, y también en algunos espacios que podríamos denominar peri-urbanos. Desde luego, éstas son distinciones que nos permitimos marcar para un mejor ordenamiento del texto, y sobre todo, para destacar algunas particularidades específicas. Pero debemos recordar que en el interior Chaco de esta época no había grandes diferencias en la manera de comportarse entre los residentes urbanos y los rurales. Todos, directa o indirectamente vivían de la producción agrícola, por lo tanto las conversaciones y los intereses giraban en torno a este tema, y no había lugar para eufemismos ni falsos refinamientos. Por ello es que a menudo se compartían los mismos espacios de sociabilidad, al margen de los orígenes, ámbitos de residencia, o condición social. Esta fue una característica 
muy común en el interior del Chaco y se mantuvo durante mucho tiempo, porque independientemente de la procedencia de los pobladores, la mayoría de ellos arribó en la misma situación de necesidad, y ello impidió que se produjera una segmentación excluyente. No obstante, y aunque prevaleció una mutua tolerancia, hacia la década del cuarenta -y en ciertos ámbitos- ya comenzaron a insinuarse algunas acciones tendientes a distinguir las clases sociales que estaban asomando en el contexto próspero del Chaco. Esto ocurría especialmente en aquellos lugares en donde no mediaba la presencia reguladora de una institución social o deportiva.

Ahora bien; en los ámbitos estrictamente rurales, es decir, en aquellos espacios más alejados de las colonias o centros poblados, la interacción grupal tuvo sus propias singularidades debido a la natural escasez de posibilidades de contacto, y sobre todo, a las limitadas opciones de entretenimiento. Aquí había un escenario caracterizado por la presencia mixta de colonos y braceros; obrajeros y hacheros; ganaderos y peones, los cuales esporádicamente también necesitaban momentos de esparcimiento y contacto social. Estas oportunidades de reunión colectiva se producían por lo general espontáneamente, o bien con una precaria organización en caso de fiestas o celebraciones especiales. No había instituciones aglutinantes, ni tampoco lugares fijos para ello. Los puntos de reunión eran, por lo general, parajes bien conocidos por los lugareños en donde había un conjunto de casas de adobe que servían como centros de provisión, y también de lugares de encuentro y entretenimiento. Allí había invariablemente un "boliche", especie de "pulpería" en donde se bebía "al copeo", y se jugaba a los naipes (El truco), y a las "bochas". Eran también muy frecuentes las riñas de gallos, el juego de "taba", ${ }^{5}$ y las carreras "cuadreras". ${ }^{6}$ El cierre de estas jornadas festivas se hacía con bailes basados especialmente en la música popular correntina o paraguaya. La música folklórica santiagueña se escuchaba también a menudo, pero no se utilizaba en estas "bailantas" porque no posibilitaban el baile entrelazado. En ocasiones, si había alguna colectividad europea predominante se ejecutaban también las músicas nativas, todo siempre animado por intérpretes aficionados agrupados al efecto. Estas reuniones, tanto las habituales como las realizadas en ocasión especial, culminaban casi siempre con incidentes debido a la rusticidad del componente

\footnotetext{
${ }^{5} \mathrm{La}$ "taba" es un hueso pequeño de la pata del vacuno, que tiene dos lados planos distintos. Es arrojada para adelante, y dependiendo del lado que caiga, será suerte o mala suerte para el tirador. Se juega por apuestas.

${ }^{6}$ Las "cuadreras" son carreras de -generalmente- dos caballos, en unos doscientos metros. En esa época, eran espontáneas, y cada jinete corría en el propio "montado" en el que llegaba. Respondían a un desafío del momento, y siempre se apostaba.
} 
social involucrado, al exceso de alcohol, y a la insuficiente o nula vigilancia policial, pero sobre todo, a la libertad disponible para portar armas blancas o de fuego. Por ello, no era algo excepcional que estas jornadas finalizaran con hechos de sangre.

De cualquier manera, y a pesar de estas sombras, como una primera síntesis de este relato debemos resaltar que el proceso de integración social ocurrido en el Chaco no tuvo mayores restricciones y se produjo casi naturalmente en un espacio que por ser de reciente ocupación, careció de condicionantes culturales que lo impidieran. Indudablemente incidió en ello el contexto de prosperidad excepcional que caracterizó al Chaco en esta época, pero en cualquier caso, es de destacar la generalizada predisposición de los diferentes grupos para adaptarse a esta tierra de adopción, y tomar como propios, hábitos, costumbres, y aún tradiciones que no eran las de sus ancestros.

\section{A modo de síntesis}

El poblamiento "blanco" del Chaco estuvo íntimamente asociado a los ciclos económicos que lo caracterizaron durante la primera mitad del siglo 20, y la atracción generada por estos procesos impulsó una notable afluencia humana que provino desde diversos países, y también de espacios circundantes al territorio. Esta corriente tuvo durante su segunda etapa, una composición multiétnica y un comportamiento aluvial, dando origen a un proceso muy singular, aún considerándolo dentro de los lineamientos generales que caracterizaron el poblamiento de los demás territorios nacionales. La heterogeneidad de los grupos que integraron el naciente cuerpo social del Chaco fue su característica sobresaliente durante la mayor parte del siglo 20 , y por ello es que se lo ha considerado como uno de los espacios más representativos del "crisol de razas" en la Argentina.

Frente al inicial interés de conocer un poco más sobre las características generales de estos grupos; de sus condiciones y formas de vida, y sus mecanismos de integración, debemos señalar que durante el transcurso de esta pesquisa hemos podido comprobar algunas constantes que ameritan ser destacadas. La afluencia inmigratoria se produjo en períodos de tiempo relativamente breves y de manera repentina, con un componente social que -independientemente de sus procedencias--, arribó con las mismas necesidades y propósitos. Dicha situación de origen operó como una fuerza igualadora en esta naciente sociedad. De allí que desde un principio no hubo lugar para una segmentación social acentuada, y además, las propias necesidades de 
colaboración recíproca en un territorio en donde todo estaba por hacerse, facilitaron una mejor predisposición a la adaptación y a la integración. Ello pudo notarse especialmente dentro del ámbito de algunas instituciones que surgieron con un propósito eminentemente pragmático, pero que a poco de constituirse se convirtieron en núcleos propiciantes del contacto social multiétnico, como lo fueron, por ejemplo, las asociaciones mutualistas, y más aún, las cooperativas agrícolas.

En aquellos espacios en donde no medió la presencia aglutinante de estas entidades, como en los estrictamente rurales por ejemplo, el proceso de integración tuvo la misma tendencia positiva, sólo que en estos casos se produjo mediante formas más espontáneas, y con prácticas un poco más rudimentarias. El "mosaico multicultural integrado" fue así mucho más que una mera expresión retórica. En el Chaco se evidenció en todas sus formas, habiendo implantado cada grupo su impronta característica en la paleta identitaria de este espacio. La coexistencia multiétnica se logró así, desde un principio, a tal punto que las expresiones que aluden a la coloración de la piel, "gringo" o "negro" (por los criollos), son habituales y carecen de connotación despectiva. Demostraciones elocuentes de esta realidad se observan hasta hoy en el Chaco, en donde es posible percibir las diferencias existentes en las tonadas del lenguaje; en las costumbres y el folklore; modos de vestir y de expresarse, y hasta en las comidas, según la zona por la que se transite. Las influencias culturales recibidas están presentes y muy vivas, particularmente en los ámbitos rurales, en donde aún puede comprobarse nítidamente este legado.

\section{Referencias}

BECK, Hugo. Inmigrantes europeos en el Chaco: transición del pluralismo al crisol. Cuadernos de Geohistoria Regional, v. 39. Resitencia: Instituto de Investigaciones Geohistóricas-Conicet, 2001.

BORRINI, Héctor. La colonización como fundamento de la organización territorial del Chaco (1930-1953). Cuadernos de Geohistoria Regional, n. 19. Resitencia: Instituto de Investigaciones Geohistóricas-Conicet, 1987.

LESTANI, Juan Ramón. El territorio nacional del Chaco: geográfico, económico, social. (Oro y miseria). Resistencia: s. ed., 1935.

MIRANDA, Guido. Tres ciclos chaqueños. Crónica Histórica Regional, ResistenciaChaco, Ed. Norte Argentino, 1955.

PAVLOTZKY, José. Esta tierra es mía. Buenos Aires: El Ateneo, 1947.

SUÁITER MARTÍNEZ, Francisco. Los territorios. Buenos Aires: Instituto Cultural Joaquín V. González, 1943. 


\section{Publicaciones oficiales}

República Argentina. Ministerio del Interior. Asesoría Letrada de Territorios Nacionales. Censo general de los territorios nacionales, 1920. Tomo 1. Bs. As., Establec. Gráf. A de Martino, 1923.

República Argentina. Tercer Censo Nacional 1914., Tomo V. Bs. As., Tall Gráf. Rosso, 1917.

República Argentina, Ministerio de Agricultura, Junta Nacional del Algodón. Cosecha Mecánica del Algodón. Estudio preparado por los Ingenieros Agrónomos Rafael García Mata y Rómulo Franchelli. Buenos Aires, 1942

Código Rural para los Territorios Nacionales; Recopilación realizada por Máximo Reyna, 1902-1910. Ministerio del Interior, Bs.As., 1910.

Archivo Histórico de la Provincia del Chaco (A.H.P.CH.). Gobernación del Chaco. Memorias Presentadas al Superior Gobierno de la Nación por el Gobernador José Castells, correspondientes a los años 1934, 1935, y 1936. Resistencia.

AHPCH, Copiadores de la secretaría de la gobernación, Gobernador Castells. $1^{\mathrm{O}} \mathrm{de}$ diciembre de 1933, p. 113.

Gobierno del territorio nacional del Chaco: Album gráfico descriptivo, Buenos Aires, 1935.

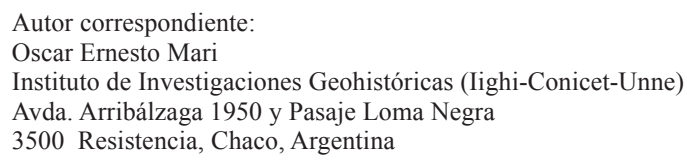

